\title{
Reflections on the Cultivating Countermeasures of Compound Talents of English Majors in Colleges and Universities
}

\author{
Sun Huimin \\ Foreign Language College of BeiHua University, Jilin City, China
}

\begin{abstract}
Keywords: Cultivating Countermeasures, Compound Talents, English Majors, Colleges and
\end{abstract} Universities

\begin{abstract}
At present, there are some problems in the cultivation of English majors in colleges and universities, such as fuzzy generalization, professional setting and covariance, curriculum departure from reality and students' ability, and narrow employment. We should through the renewal of ideas, clear objectives, reform of professional education system, the implementation of supply and demand combined with training mode, minor secondary professional degree model and strengthen the construction of teachers and other measures to solve.
\end{abstract}

\section{Introduction}

The rapid development of science and technology and the cross of science, blending, infiltration of our foreign language undergraduate education is facing the challenges of the era of knowledge economy. In order to meet the social, economic, cultural and technological development, in order to meet this challenge, a new formulation "to cultivate composite talents" came into being. "A number of opinions on the reform of undergraduate education in foreign languages for the 21st century" pointed out that "due to the unbalanced development of the institutions, the model, content and process of the training of compound talents must also vary from school to school. What is the meaning of the compound talents' reference to the normal colleges? What countermeasures should be taken? This is the focus of this paper.

\section{The Orientation of Compound Talents Training Mode for English Major in Colleges and Universities}

The cultivation of compound talents of English major in colleges and universities should always grasp the training objectives and specifications of normal colleges and universities. This is the consensus of many teachers and academics. Our training objectives are clear: to cultivate a solid foundation of basic theory of English, basic knowledge and basic skills; to the use of pedagogy, the basic theory of psychology has good teacher professionalism, to meet the needs of the development of modern socialist people's teachers. From this training goal, our normal school students in the beginning there is a basic, with a signed nature of career orientation. Most graduates are engaged in educational work as a teacher. And in the "science and education" under the current situation, with the enactment of teacher law and teacher qualification certificate system in China formally implemented, the teacher profession as a professional status has been confirmed. The employment rate of normal students is still considerable. In recent years, our college English professional graduates distribution point of view, more than $90 \%$ of graduates signed on the education front, the employment rate is still 100\%. Compared to non-normal English graduates, our students' employment pressure is much smaller. But we cannot deny that normal colleges and universities in the English education reform is also facing a serious challenge. This challenge comes from both non-normal institutions, but also from some of the rise, the maturity of all kinds of private schools. This shows that teacher training in the future will no longer be a normal university patent, Industry advantage will be greatly reduced, will face a strong competition. Therefore, our normal colleges and universities should make a fuss about the teacher, give full play to the advantages of teachers colleges and universities to cultivate teachers, and explore the new ways of cultivating talents of English majors in normal colleges. 
The foreign language talents in the 21st century should have a solid basic skills, broad knowledge, certain professional knowledge, strong ability and good quality. "According to the goals and specifications of normal colleges and universities, our graduates have a certain combination of talent characteristics: English professional knowledge + teaching professional skills + teachers comprehensive quality. Therefore, we should not blindly pursue, imitate the non-normal colleges and universities are testing the complex foreign language professionals training mode: foreign language + professional, professional + foreign language and double degree. The key question of the cultivation of foreign language talents in normal colleges is not how to make graduates both foreign teachers and managers, but how to cultivate qualified foreign language teachers who meet the needs of the 21st century. Therefore, the training of compound talents of English majors in normal colleges and universities should strive to equalize the professional quality and professionalism, try to change the traditional educational ideas and ideas, change only focus on the intellectual education of students to cultivate the idea of "knowledge, ability, Coordinated development and "do learning, work, life" coordinated development of educational thinking. English as the basic material of English complex professional English should be a professional English level of English teaching and language skills. In this way, we can further write the above structure:

\begin{tabular}{|ccc|}
\hline & \multicolumn{2}{c|}{ (Variable) Reinforcing material } \\
Language and Literature & International Business legal C Technology \\
\hline Profession & English (Language, Communication Habits, Culture) \\
& (Changeless) Base material \\
\hline
\end{tabular}

With the text that is, with professional English ability and professional business knowledge of the composite teaching structure, the final product is what we call the English compound talents.

\section{The Current Problems of College English Professional Talents Training}

In the "English undergraduate professional training program", the English professional training objectives: "to cultivate moral, intellectual, physical and aesthetic development, to adapt to national economic construction and social development needs, with a solid basic English skills, broad knowledge Students, after graduation, proficient in the use of English in business, education, tourism, news, information, and so on. The students are able to use English in the business, education, tourism, Research and other departments engaged in translation, management, teaching, research and so on. "From this goal, it does not highlight the English professional can be applied to any kind of professional training objectives; its basic skills or knowledge of the requirements are too general, and did not put forward specific standards; its training objectives and English professional training content does not match. This will affect the specific implementation of the English language teaching objectives training program, resulting in the teaching process is not clear, the teaching requirements cannot be determined and the teaching content cannot be unified with the teaching objectives.

In the wave of popularization of higher education in China, many institutions have been merged, upgraded and transformed, resulting in a lot of problems. First of all, according to statistics, Chinese full-time undergraduate institutions in $90 \%$ of the institutions with English majors, and most institutions of English professional settings do not take into account the characteristics of the school, the professional settings between the same institutions, resulting in excess English graduates, employment and other consequences. Secondly, the homogeneity of English professional training and the goal of training is very serious. All the design of English major is aimed at copying the English syllabus of English for English, which does not reflect the characteristics of the school and the local economic and social development the characteristics of demand.

Course setting is the cornerstone of a professional building. Whether the curriculum is scientific, reasonable, directly related to the professional training of students can meet the needs of society and business. Most College English Courses in Our Country Are Departed from Practice. According to the survey, language skills training courses accounted for two-thirds (67\%) of English majors, and 
other professional courses and related professional courses accounted for only\% and 18\% respectively. This makes it difficult for English majors to truly have a "professional" outside of language skills, and it is difficult to be competitive in the talent market. This serious departure from the actual curriculum makes students in the school a lot of time in the study of English professional knowledge, and the lack of a practical application of the skills of the opportunity, which is caused by most of the graduates of the graduates of the important reasons for the unemployment situation one.

At present, most colleges and universities in English teaching is still the traditional model, too much emphasis on foreign language professional knowledge, only focus on the basic skills of foreign language training, lack of interdisciplinary intercourse, integration and penetration, ignoring the ability of students to analyze problems and innovation Of the training, cannot meet the needs of social development, leading to a single student ability, after graduation, narrow employment

\section{The Necessity to Cultivate Compound English Talents}

First of all, with the rapid development of Chinese social economy in recent years, the demand for foreign language talents has increased dramatically, while foreign trade and economic activities are extremely limited. Therefore, foreign language students should not only confined to lexical, grammar and other language skills learning, must be with the social and political, economic development and enrich their ability and quality, so that they become understand the economy, management and computer and other disciplines of the compound talents.

Second, the cultivation of complex talents is also the inevitable reform of Chinese education system. As the talent market for the simple language and literature graduates of the demand is gradually reduced, and the application type, a large number of complex talents needs, our education system should also be a corresponding reform, regardless of the English professional theory courses or practice courses should be with the market Convergence, focusing on the cultivation of English professional talents.

Finally, in recent years, the severe employment situation of English majors requires the cultivation of compound talents. Since the expansion of major colleges and universities in 1999, the surge in English talent, while the traditional employment industry near saturation. In recent years, English major has been listed among the high unemployment rate of professional, simple talent is almost impossible to find counterparts career. Therefore, the cultivation of English compound talents will greatly alleviate the severe employment situation of English majors.

\section{The Cultivation Strategy of English Professional Talents}

Update Ideas and Clear Goals. In foreign language teaching practice, we should first update the concept of teaching staff, determine the modern educational ideas, clearly cultivate the goal of compound talents and change the original training of English teachers and specialized translation of a single goal.

Reform the Professional Education System. At present, college English professional education system is divided into three levels, namely, professional education level, general education level and comprehensive education level. (Including language, literature and culture courses); general education includes advanced mathematics, university computer foundation (including language, literature, culture courses); general education, including English majors (including training, speaking, reading, writing and translation skills) and English professional knowledge courses And programming and the basic principles of Marxism and other courses; comprehensive education, including human education and military training and sports standards such as courses. I believe that in the professional education system should increase the practical ability of students to develop the composition of the curriculum, strengthen the practice of teaching links and optimize the professional curriculum. Thus, it is recommended to establish the following three modules: professional education module, cultural training module and education practice module.

The professional education module is proposed to be divided into three phases. 1 grade for the 
first stage, to teach students the basic knowledge and skills of English, open English, voice, listening, reading, spoken and English grammar and other English language and literature backbone courses to strengthen the basic skills of students. The second stage begins with the second grade, on the basis of compiling the basic knowledge and skills of English, to further expand the students' knowledge, and through teaching students language theory and other research methods imperceptibly teach students to solve the problem of scientific thinking, this stage can be traditional The introduction of English linguistics, lexicology, stylistics and translation theory and practice and other professional theory courses. The third stage in the 3-4 grade and it is recommended to set up practical courses, including science and technology English translation, English teaching methods and statistics. In particular, statistics can be applied to many areas, this course cannot only enhance the intention of the development of English professional students interested in the cultivation of scientific research capacity, and if not after graduation students can learn more skills. In addition, it is recommended to delete the reading-related subjects such as English Extensive Reading and Foreign Newspaper Readings in the second and third stages, because there are first-stage teachers to read the scope of reading and reading materials on the basis of reading skills and reading appreciation can be arranged in autonomous learning subjects, English stylistics and English and American literature subjects; also suggested that English interpreting practice into the educational practice module, the school provides a specific practice environment, so that students can in the real social environment, exercise interpretation skills, while strengthening the comprehensive ability to exercise.

Cultural training module aims to help students broaden their horizons, enhance cultural quality and accomplishment. This stage can be set up Anglo-American profile, English literary works selected, the European cultural people and the Greek and Roman mythology courses. Moreover, taking into account the students after graduation as a language intermediary role into social work, so not only to understand the history of Western culture, but also should understand the connotation of Chinese language and culture, so this stage should also open modern Chinese, ancient Chinese, contemporary Chinese literature and folklore research and other related Chinese language and culture courses. At the same time, it is proposed to set up Western etiquette, Chinese and foreign music culture audio-visual, foreign language film appreciation and other courses to cultivate students personal culture.

The educational practice module aims to develop students' language application ability, thinking innovation ability and practical work ability. In addition to the opening of the main courses, English academic papers writing, but also should carry out the second classroom practice teaching activities, such as the English Corner, Oral Association, Translation Association, Foreign Language and Culture Festival, voice training group and autonomous learning center, Various English competitions, including English drama, English dubbing, English speaking and English writing, and social practice, for students to create foreign affairs reception, community volunteer tutor or to the factory translation practice and other opportunities.

Implement the Combination of Supply and Demand Training Mode. University Personnel Training should work closely with the needs of the job market. Today, many institutions try "order" training mode, some colleges and universities work together to develop training programs, enterprises put forward the specific requirements of the quality of talent, and provide students with practical practice opportunities, colleges and universities on-demand teaching. In this way, students in the learning stage not only have the opportunity to apply the theoretical knowledge for practice, while in the employment before the understanding of corporate culture, production processes and other aspects of the content, saving business training time and reduce the cost of human resources. In this way, for enterprises and students "tailor-made" training program, not only effectively solve the problem of employment difficult graduates, more enterprises to quickly enter the "role" of the talents.

Minor Secondary Professional Degree Model. The main course, undergraduate and other specialties, such as foreign affairs, trade, law and management, after the completion of the provisions of the credit, the difference between this approach and the multi-disciplinary approach is 
that there is no need to complete all the second or third professional courses, just take their professional major professional courses, access to foreign language professional expertise, which is a practical (2) the course of elective courses. The advantage of elective courses is the choice of students, students can be based on social, political and economic and other environmental needs and personal interests, elect their own interest in non-foreign language courses the elective course is the easiest way to cultivate talents. (3) The qualification certificate is the proof that the holder has the expertise and skill needed for a certain occupation. It is the recruitment and recruitment of the employing unit. The main basis of the staff should encourage foreign language students to obtain a variety of qualifications during the school students in the preparation of the relevant qualification certificate prepared to review In, will concentrate on targeted training themselves, proven, this is a foreign language training compound talents the most efficient and practical way.

Strengthen the Construction of Teachers. First of all, it can be taken home and abroad to learn the way teacher training. Foreign language professional teachers can use the national study fund and other means to foreign related professional training, but also to the domestic institutions of higher learning for domestic exchange of scholars, to have more experience in colleges and universities to learn, exchange, to understand how other institutions are compound talents training. Second, the school can take the way to train teachers. In the institutions of higher learning, between the various departments can be implemented between the sharing of resources, foreign language colleges and other colleges and universities can work together to set up professional courses and professional elective courses, make full use of other resources within the school for foreign language students to open related courses, hire other faculties the teachers take courses, foreign language students more specialized and complex knowledge education.

\section{Conclusion}

English is a popular profession and many colleges and universities have opened it, simply on the professional itself, its features not obvious. In terms of applied universities, the construction of English specialties should serve the breakthrough of the local social and economic development needs of the local areas. We should have the courage to reform and innovate, from the guiding ideology, cultivating the model, cultivating the characteristics, the curriculum system and the student self- and compound training model and so on to create the compound application talents mode in English majors.

\section{References}

[1] Ning Qiang: Higher Education in Heilongjiang Province, Vol. 6 (2004) No 53, p.25-26

[2] Xue Zhang: Foreign Language Teaching in Shandong Province, Vol. 12 (2005) No 27, p.74-76

[3] Cao Ruiming: Higher Education, Vol. 1 (2006) No 33, p.11-14

[4] Jieming Liu: Foreign Language Explorers, Vol. 3 (2007) No33, p.121-124

[5] Jia Xinzhang, Li Jingyuan. Foreign Language Teaching, Vol. 6 (2014) No 53, p.25-26 